\title{
Fotossíntese e taxa diária de produção de forragem em pastagens de capim-tanzânia sob lotação intermitente
}

\author{
Gustavo José Braga( ${ }^{(1)}$, Alexandre Carneiro Leão de Mello(2), Carlos Guilherme Silveira Pedreira ${ }^{(3)}$ \\ e Henrique Rocha de Medeiros ${ }^{(4)}$
}

\begin{abstract}
(1)Agência Paulista de Tecnologia dos Agronegócios, Pólo Regional de Desenvolvimento Tecnológico dos Agronegócios do Centro-Oeste, Rua Sebastião Soares, s/no, CEP 17380-000 Brotas, SP. E-mail: gjbraga@apta.sp.gov.br (2)Universidade Federal Rural de Pernambuco, Departamento de Zootecnia, Rua Dom Manoel de Medeiros, s/no, Dois Irmãos, CEP 52171-030 Recife, PE. E-mail: mello@dz.ufrpe.br ${ }^{(3)}$ Escola Superior de Agricultura Luiz de Queiroz, Departamento de Zootecnia, Avenida Pádua Dias, no 11, CEP 13418-900 Piracicaba, SP. E-mail: cgspedre@esalq.usp.br ${ }^{(4)}$ Embrapa Caprinos, Estrada Sobral-Groaíras, Km 04, CEP $62010-970$ Sobral, CE. E-mail: hrdemedeiros@yahoo.com.br
\end{abstract}

Resumo - O objetivo deste trabalho foi avaliar o efeito da intensidade de pastejo na taxa diária de acúmulo de forragem e na fotossíntese foliar líquida do capim-tanzânia, em pastagens manejadas sob lotação intermitente. O experimento foi conduzido de novembro de 1999 a outubro de 2000, em delineamento de blocos ao acaso, com quatro repetições. Os tratamentos experimentais foram três quantidades de massa de forragem verde remanescente $\left(1.000,2.500\right.$ e $\left.4.000 \mathrm{~kg} \mathrm{ha}^{-1}\right)$, aplicados em ciclos de pastejo de 36 dias (33 de descanso e 3 de ocupação). A taxa diária de acúmulo de forragem não sofreu efeito da intensidade de pastejo e, com exceção no inverno, foi mais elevada nos primeiros 11 dias da rebrotação e nos períodos com temperaturas mais elevadas. A fotossíntese foliar líquida também não sofreu efeito da intensidade de pastejo (média de $23,2 \mu \mathrm{mol} \mathrm{m}^{-2} \mathrm{~s}^{-1}$ de $\mathrm{CO}_{2}$ ) e aumentou no decorrer da rebrotação, com os maiores valores entre o 11 e e 22 을 dias de rebrotação, nas diferentes épocas do ano. A fotossíntese foliar líquida variou com as alterações ocorridas na estrutura do dossel, durante o desenvolvimento das folhas. A utilização de períodos de descanso fixos impediu que houvesse alterações na taxa de acúmulo de forragem causadas pela intensidade de pastejo.

Termos para indexação: Panicum maximum, altura do dossel, estrutura do dossel, índice de área foliar, massa de forragem.

\section{Photosynthesis and daily forage productivity of Tanzania guinea grass pastures under rotational stocking}

\begin{abstract}
The objective of this study was to evaluate the effects of grazing intensity on forage accumulation rate and on net leaf photosynthesis of Tanzania guinea grass (Panicum maximum Jacq.) pastures under rotational stocking. The experiment was carried out from November 1999 to October 2000, in a randomized complete block experimental design, with four replications. Treatments were three levels of residual green forage biomass $\left(1,000,2,500\right.$, and 4,000 $\mathrm{kg} \mathrm{ha}^{-1}$ ) in grazing cycles of 36 days (33 days of rest and 3 days of grazing). Forage accumulation rate was not affected by grazing intensities, and it was highest in the first 11 days of regrowth during the periods of the highest temperatures. Net leaf photosynthesis was not affected by grazing intensity (mean $23.2 \mu \mathrm{mol} \mathrm{m} \mathrm{m}^{-2} \mathrm{~s}^{-1} \mathrm{CO}_{2}$ ) and increased during regrowth with the highest values between the $11^{\text {th }}$ and the $22^{\text {nd }}$ days of rest, depending on the season of the year. Net leaf photosynthesis was correlated with sward structure changes, during leaf development. The use of fixed rest periods avoided alterations of forage accumulation rate caused by grazing intensity.
\end{abstract}

Index terms: Panicum maximum, sward height, sward structure, leaf area index, forage mass.

\section{Introdução}

O capim-tanzânia (Panicum maximum Jacq. cv. Tanzânia-1) foi lançado pela Embrapa em 1990, e hoje é uma cultivar forrageira bastante cultivada no Brasil, com importante participação no comércio nacional de sementes (Macedo, 2004). A cultivar possui elevada capacidade de produção de forragem e é recomendada para uso na criação de bovinos em sistemas sob lotação intermitente (Santos et al., 1999), mas vem sendo utilizada também em sistemas sob lotação contínua (Barbosa et al., 2006). Em lotação intermitente, Pedreira et al. (2005) verificaram produção média de 
$18.000 \mathrm{~kg} \mathrm{ha}^{-1}$ de matéria seca (MS), nos meses de dezembro a julho.

Em razão da elevada produção de forragem e do hábito de crescimento cespitoso, o manejo do capimtanzânia exige cuidados, especialmente no que diz respeito ao excessivo crescimento dos colmos (Santos et al., 2003b), que pode influenciar negativamente no crescimento posterior das plantas (Braga et al., 2006) e reduzir o acúmulo de forragem. Ao mesmo tempo pode modificar a estrutura do dossel, de modo a prejudicar o consumo de forragem e o desempenho animal (Alexandrino et al., 2005). A intensidade de pastejo pré-estabelecida deve operar como controle para proporcionar condições adequadas ao acúmulo de forragem e ao desempenho dos animais.

Alterações na estrutura do dossel, provocadas pelo manejo do pasto, além das mudanças no dossel típicas de sistemas sob lotação intermitente, modificam o ambiente luminoso em que as folhas e demais tecidos das plantas se desenvolvem, o que influencia a fotossíntese foliar líquida durante os períodos de rebrotação (Prioul et al., 1980a; Parsons et al., 1988b). Estudos têm demonstrado que, durante a rebrotação, a fotossíntese foliar líquida nas folhas novas e expandidas aumenta até determinado ponto, até que se inicia sua redução. Imediatamente após o pastejo, apesar do reduzido sombreamento, as folhas remanescentes apresentam reduzida fotossíntese, provavelmente em razão de seu desenvolvimento ter ocorrido parcialmente sob intenso sombreamento (Peri et al., 2003; Pedreira \& Pedreira, 2007). O hábito de crescimento cespitoso pode minimizar esse efeito em razão do crescimento ereto e da abundante oferta de luz nos estratos superiores do dossel, mesmo quando o índice de área foliar (IAF) é elevado (Pedreira \& Pedreira, 2007).

$\mathrm{O}$ estudo do acúmulo de forragem em sistemas sob lotação intermitente é um importante meio para se entender a interação de plantas e animais na pastagem. A fotossíntese foliar verificada nesse sistema ainda é pouco estudada em ambientes tropicais.

Este trabalho teve como objetivo avaliar o efeito da intensidade de pastejo na taxa diária de acúmulo de forragem e na fotossíntese foliar líquida, em pastagens de capim-tanzânia manejadas sob lotação intermitente.

\section{Material e Métodos}

O experimento foi conduzido na Fazenda Areão, pertencente à Escola Superior de Agricultura Luiz de
Queiroz (USP-Esalq), em Piracicaba, SP (22\%42'30"S; $47^{\circ} 38^{\prime} 30^{\prime \prime} \mathrm{W}$ e $576 \mathrm{~m}$ de altitude), entre novembro de 1999 e outubro de 2000, em uma área de 4,8 ha de capim-tanzânia (Panicum maximum Jacq. cv. Tanzânia), irrigada por pivô central. O clima do local, segundo a classificação de Köppen, é do tipo Cwa (tropical úmido com três meses mais secos: junho, julho e agosto), com chuvas de verão (Tabela 1). O solo da área, classificado como Nitossolo Vermelho de textura franco-argilosa (Embrapa, 1999), teve suas características químicas avaliadas na camada de $0-20 \mathrm{~cm}$ em outubro de $1999 \mathrm{e}$ tem as seguintes características: $\mathrm{pH} 4,8 ; \mathrm{MO}, 24 \mathrm{~g} \mathrm{dm}^{-3}$; $\mathrm{P}, 17 \mathrm{mg} \mathrm{dm}^{-3} ; \mathrm{S}^{-\mathrm{SO}_{4}}, 11 \mathrm{mg} \mathrm{dm}^{-3} ; \mathrm{K}, 3,9 \mathrm{mmol}_{\mathrm{c}} \mathrm{dm}^{-3}$; $\mathrm{Mg}, 16 \mathrm{mmol}_{\mathrm{c}} \mathrm{dm}^{-3} ; \mathrm{Al}, 1,0 \mathrm{mmol}_{\mathrm{c}} \mathrm{dm}^{-3} ; \mathrm{H}+\mathrm{Al}$, $38 \mathrm{mmol}_{\mathrm{c}} \mathrm{dm}^{-3}$; SB, $64 \mathrm{mmol}_{\mathrm{c}} \mathrm{dm}^{-3}$; T, $102 \mathrm{mmol}_{\mathrm{c}} \mathrm{dm}^{-3}$; $\mathrm{V}$ e $\mathrm{m}, 63$ e $2 \%$, respectivamente. $\mathrm{O}$ solo foi preparado entre janeiro e março de 1999 e, antes da semeadura, recebeu calcário, fosfato e potássio, para atingir valores próximos de $80 \%$ de saturação por bases, $25 \mathrm{mg} \mathrm{dm}^{-3}$ de fósforo (P) e 5\% da CTC com potássio (K). Após o estabelecimento, as irrigações passaram a ser controladas com o uso de tensiômetros. Foram instaladas dez baterias de seis tensiômetros, nas profundidades de $0,1,0,2,0,4,0,6,0,8$ e $1,0 \mathrm{~m}$. As leituras foram realizadas diariamente, até as $8 \mathrm{~h}$, e quando os tensiômetros instalados a $0,2 \mathrm{~m}$ indicavam valores médios de 0,3 a 0,4 bar de tensão de água no solo, era realizada irrigação.

Os tratamentos foram representados por três quantidades de massa de matéria verde remanescente seca (MVS) pós-pastejo $(\mathrm{T} 1=1.000, \mathrm{~T} 2=2.500$ e $\mathrm{T} 3=4.000 \mathrm{~kg} \mathrm{ha}^{-1}$ de MVS). $\mathrm{O}$ delineamento experimental utilizado foi o de blocos ao acaso, com

Tabela 1. Dados climatológicos observados em Piracicaba, SP, no período de novembro de 1999 a outubro de 2000.

\begin{tabular}{lcccc}
\hline Mês/ano & $\begin{array}{c}\text { Temperatura Temperatura } \\
\text { média }\left({ }^{\circ} \mathrm{C}\right)\end{array}$ & $\begin{array}{c}\text { Temperatura } \\
\text { máxima }\left({ }^{\circ} \mathrm{C}\right)\end{array}$ & $\begin{array}{r}\text { Precipitação } \\
(\mathrm{mm})\end{array}$ \\
\hline Novembro de 1999 & 21,6 & 28,9 & 15,4 & 51,6 \\
Dezembro de 1999 & 23,7 & 30,2 & 18,8 & 261,5 \\
Janeiro de 2000 & 23,4 & 29,7 & 18,9 & 224,1 \\
Fevereiro de 2000 & 23,5 & 29,6 & 19,4 & 117,1 \\
Março de 2000 & 22,8 & 29,1 & 18,6 & 166,5 \\
Abril de 2000 & 21,5 & 28,8 & 15,1 & 1,1 \\
Maio de 2000 & 18,4 & 26,1 & 11,9 & 4,8 \\
Junho de 2000 & 18,5 & 26,7 & 11,3 & 5,2 \\
Julho de 2000 & 16,0 & 24,1 & 9,1 & 61,0 \\
Agosto de 2000 & 19,0 & 27,1 & 12,1 & 25,0 \\
Setembro de 2000 & 20,3 & 26,8 & 15,1 & 88,9 \\
Outubro de 2000 & 24,2 & 29,8 & 17,7 & 102,7 \\
\hline
\end{tabular}

Fonte: Base de dados da estação meteorológica automatizada, Área de Física e Meteorologia, LCE-Esalq-USP. 
quatro repetições. Para o pastejo, foram utilizados bovinos manejados sob lotação intermitente, com ciclos de pastejo de 36 dias, com três dias de ocupação e 33 dias de descanso. As taxas de lotação em cada tratamento e ciclo de pastejo foram definidas em razão da massa de forragem no pré-pastejo e a quantidade de massa de matéria seca remanescente, definida conforme cada tratamento. Em razão dos ajustes da taxa de lotação nos ciclos de pastejo, as médias verificadas foram $1.518,2.902$ e $4.220 \mathrm{~kg} \mathrm{ha}^{-1}$ de MVS, respectivamente, para as quantidades pré-estabelecidas de $1.000,2.500$ e $4.000 \mathrm{~kg} \mathrm{ha}^{-1}$ de MVS.

A área experimental de 4,8 ha foi dividida em 12 parcelas de 0,4 ha e cada uma foi subdividida em três piquetes de $0,133 \mathrm{ha}$, a fim de permitir o ciclo de pastejo pré-estabelecido. Após cada pastejo, as parcelas receberam adubações de $80 \mathrm{~kg} \mathrm{ha}^{-1}$ de $\mathrm{N}$ e $80 \mathrm{~kg} \mathrm{ha}^{-1}$ de $\mathrm{K}_{2} \mathrm{O}$. Foram coletados dados de nove ciclos de pastejo (rebrotação de 33 dias), com início no pós-pastejo do ciclo $1(5 / 11 / 1999)$ e término no pré-pastejo do ciclo 10 (30/10/2000). O ciclo de pastejo 9 não foi avaliado, porque não foi possível a manutenção dos animais na área experimental, em razão da ocorrência de uma geada. Foram realizadas avaliações em quatro dias do período de rebrotação $\left(1^{\circ}, 11^{\circ}, 22^{\circ}\right.$ e $33^{\circ}$ dias após a saída dos animais), a fim de traçar curvas de respostas em cada rebrotação (ciclos de pastejo) e em cada estação do ano. As medições ocorreram em piquetes representativos da condição média de cada tratamento durante o período experimental.

A altura do dossel foi estimada como a média de 50 medições por piquete, em cada dia de amostragem. Essas leituras foram realizadas na inflexão da folha mais alta da planta. Para as avaliações de índice de área foliar (IAF) e interceptação de luz (IL), utilizouse o analisador de dossel LAI-2000 (LI-COR, Lincoln, Nebraska, EUA), que permite amostragens rápidas e não destrutivas (Welles \& Norman, 1991). Foram realizadas cinco leituras com o sensor no nível do solo para cada leitura com o sensor acima do dossel, em dez locais considerados representativos da condição média do piquete, num total de 50 leituras. As leituras no nível do solo foram realizadas com o sensor localizado, inicialmente, na base da touceira e, à medida que o dossel recuperava sua área foliar, as leituras foram feitas afastando-se o sensor em direção às áreas entre as touceiras. Esse procedimento foi utilizado em razão da reduzida área foliar remanescente no resíduo pós-pastejo mais baixo. A partir do $11^{\circ}$ dia esse tratamento já permitia o deslocamento do sensor da base da touceira, pois já apresentava área foliar com interceptação da luz incidente, base para o cálculo dos valores de IAF.

A taxa de fotossíntese foliar líquida e a temperatura foliar foram medidas com o sistema portátil de fotossíntese LI-6400 (LI-COR, Lincoln, Nebraska, EUA), que mede taxa líquida de fotossíntese por meio da estimativa de assimilação de $\mathrm{CO}_{2}$ pelas folhas. Em cada unidade experimental, foram realizadas 30 medições de fotossíntese foliar líquida e de temperatura foliar. Para isso, foram fixados valores de intensidade luminosa no interior da câmara de medição. Esses valores foram diferentes de acordo com a estação do ano, e seguiram a observação de um valor médio registrado no fotômetro externo do LI-6400, sempre no horário do início das medições. No verão e na primavera, foi utilizado o valor de $2.200 \mu \mathrm{mol} \mathrm{m}^{-2} \mathrm{~s}^{-1}$ de fótons. No outono e no inverno

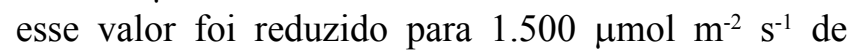
fótons. As medições foram feitas nas folhas mais novas expandidas dos perfilhos, em locais representativos da condição média da pastagem.

A massa de forragem (MF) foi determinada no $11^{\circ} \mathrm{e}$ 33ํ dia de cada rebrotação, por método direto, como a média de cinco pontos de amostragem ao longo de uma linha (Penati, 2002). Em cada ponto, a altura do dossel foi medida e, em seguida, a forragem contida dentro de uma moldura de $1 \mathrm{~m}^{2}$ foi cortada ao nível do solo. Uma subamostra foi pesada no campo, levada para secar em estufa de ar forçado a $55^{\circ} \mathrm{C}$ por 72 horas e, em seguida, pesada novamente. $\mathrm{O}$ teor de MS foi então calculado e usado para estimar a MF. Com os dados de altura e MF, no $1^{\circ}$ e $33^{\circ}$ dia de todas as rebrotações, a relação entre a altura do dossel e a MF foi estabelecida por meio de regressão linear, com os procedimentos PROC REG e PROC SORT do SAS (SAS Institute, 2001), para estimativa de MF no $11^{\circ}$ e $22^{\circ}$ dia. As taxas de acúmulo de forragem (TAF) foram calculadas pelas diferenças entre os valores de MF do $1^{\circ}$ e $11^{\circ}$ dia, do $11^{\circ}$ e $22^{\circ}$ dia e do $22^{\circ}$ e $33^{\circ}$ dia, para cada tratamento dentro dos ciclos de pastejo.

Para a análise estatística, os dados dos ciclos de pastejo foram agrupados em quatro épocas do ano. Os três primeiros ciclos de pastejo $(5 / 11 / 1999$ a 21/2/2000) foram denominados de verão; os ciclos 4 e $5(21 / 2 / 2000$ a $3 / 5 / 2000)$ foram denominados de outono; os ciclos 6 e $7(3 / 5 / 2000$ a 14/7/2000) 
foram denominados de inverno e os ciclos 8 e 10 $(14 / 7 / 2000$ e 30/10/2000) foram denominados de primavera. Os dados foram analisados como medidas repetidas no tempo pelo procedimento MIXED (SAS Institute, 2001), tendo sido considerados efeitos fixos a intensidade de pastejo, a época do ano, o período de rebrotação e suas interações. Como efeitos aleatórios foram considerados o erro experimental entre unidades e o erro para a mesma unidade no tempo. Para a análise da fotossíntese foliar líquida, a temperatura foi utilizada como co-variável. Análises de regressão linear, realizadas com o procedimento GLM (SAS Institute, 2001), foram utilizadas para a relação entre IAF e massa de forragem e entre fotossíntese foliar e altura do dossel.

\section{Resultados e Discussão}

A TAF não foi influenciada pela intensidade de pastejo $(p>0,05)$, tampouco pelas interações entre intensidade de pastejo, período de rebrotação e época do ano $(p>0,05)$. Por outro lado, a interação entre época do ano e período de rebrotação foi significativa ( $<<0,0001)$. Com exceção no inverno, quando não houve diferença significativa $(p>0,05)$, nas demais épocas do ano a TAF foi superior nos primeiros 11 dias de rebrotação (Tabela 2). A TAF média nas diferentes épocas do ano foi de 117, 106, 45 e $73 \mathrm{~kg} \mathrm{ha}^{-1}$ de MS no verão, outono, inverno e primavera, respectivamente. Ao se considerarem as médias das épocas do ano, o acúmulo de forragem foi de $34.130 \mathrm{~kg} \mathrm{ha}^{-1}$ de MS. O uso de irrigação e a alta dose de $\mathrm{N}$ proporcionaram elevada produtividade de forragem. Quando comparadas com experimentos conduzidos sem irrigação e com doses de $\mathrm{N}$ mais baixas (Gerdes et al., 2000; Pedreira et al., 2005), as TAF do capim-tanzânia alcançaram valores superiores. Em parcelas experimentais irrigadas de capim-tanzânia adubado com $300 \mathrm{~kg} \mathrm{ha}^{-1}$ de $\mathrm{N}$ foram produzidos cerca de $26.000 \mathrm{~kg} \mathrm{ha}^{-1}$ de MS entre os meses de setembro e abril, nas condições climáticas da Zona da Mata de Pernambuco (Santos et al., 2003a). Existem evidências de que o aumento da intensidade de pastejo nem sempre influencia a produção de forragem de gramíneas forrageiras tropicais (Braga et al., 2006), apesar de influenciar características morfológicas do dossel como proporção de lâminas foliares e colmos (Marcelino et al., 2006; Barbosa et al., 2007).

$\mathrm{Na}$ intensidade de pastejo mais elevada (menor massa de matéria seca remanescente), apesar da MF mais baixa no pós-pastejo, a comunidade de plantas pode ter compensado essa insuficiência, seja pelo aumento na capacidade de rebrotação (Matches, 1992) ou pelo período de descanso suficientemente longo, o qual possibilitou ao tratamento de intensidade mais elevada alcançar valor próximo de acúmulo de forragem, quando comparado aos demais tratamentos, como discutido em Parsons et al. (1988a). De modo geral, no 33으 dia do período de descanso, o dossel alcançou cerca de $100 \%$ de interceptação luminosa, o que equiparou os tratamentos e, ao mesmo tempo, indicou desaceleração do crescimento das plantas antes mesmo do final da rebrotação (Brougham, 1958). Desse modo, o uso de elevadas doses de $\mathrm{N}$ e irrigação tornou o intervalo entre pastejos excessivamente longo, especialmente no verão, que apresentou maior crescimento.

A fotossíntese foliar líquida não sofreu efeito da intensidade de pastejo e das interações entre intensidade de pastejo e os demais fatores envolvidos na análise $(p>0,05)$. No entanto, o efeito da interação entre estação do ano e do período de rebrotação foi significativo $(p<0,0001)$, assim como o efeito da temperatura foliar $(\mathrm{p}<0,0001)$. De modo geral, a fotossíntese foliar líquida máxima ocorreu no $11^{\circ}$ dia de rebrotação (Tabela 3), exceção para o $22^{\circ}$ dia do inverno $\left(28 \mu \mathrm{mol} \mathrm{m}^{-2} \mathrm{~s}^{-1} \mathrm{de}\right.$ $\mathrm{CO}_{2}$ ). Com a ocorrência desses picos durante o período de descanso os resultados foram ajustados a curvas quadráticas ou cúbicas. Entre todas as épocas do ano, a fotossíntese foliar líquida foi mais elevada durante os meses de verão (33, 21, 20 e $19 \mu \mathrm{mol} \mathrm{m}^{-2} \mathrm{~s}^{-1}$ de $\mathrm{CO}_{2}$ no verão, outono, inverno e primavera, respectivamente). Pedreira \& Pedreira (2007) verificaram, em pastagens

Tabela 2. Taxa diária de acúmulo de forragem (TAF) em pastagens de capim-tanzânia em quatro épocas (verão, outono, inverno e primavera) e sob efeito do período de rebrotação (11, do dia $1^{\circ}$ ao $11^{\circ}$ dia; 22 , do $11^{\circ}$ ao $22^{\circ}$ dia; 33 , do $22^{\circ}$ dia ao $33^{\circ}$ dia). Os polinômios ortogonais (linear e quadrático) são indicados para o efeito do período de rebrotação.

\begin{tabular}{|c|c|c|c|c|}
\hline \multirow[t]{2}{*}{ Dia de rebrotação } & \multicolumn{4}{|c|}{ Época do ano } \\
\hline & Verão & Outono & Inverno & Primavera \\
\hline & \multicolumn{4}{|c|}{ TAF $\left(\mathrm{kg} \mathrm{ha}^{-1} \mathrm{dia}^{-1}\right.$ de MS $)$} \\
\hline 11 & 119,9 & 163,8 & 49,8 & 117,1 \\
\hline 22 & 92,5 & 90,2 & 41,7 & 65,1 \\
\hline 33 & 139,5 & 64,9 & 41,9 & 35,3 \\
\hline Erro-padrão da média & 5,40 & 5,72 & 5,40 & 5,72 \\
\hline Polinômio ortogonal & \multicolumn{4}{|c|}{----------------p (probabilidade)--------------- } \\
\hline Linear & 0,1424 & $<0,0001$ & 0,5519 & $<0,0001$ \\
\hline Quadrático & 0,0018 & 0,0444 & 0,7169 & 0,3895 \\
\hline
\end{tabular}


de capim-xaraés [Brachiaria brizantha (Hochst. ex A. Rich.) Stapf.], que a fotossíntese foliar líquida aumentou até o $15^{\circ}$ dia de rebrotação, independentemente do manejo adotado, tendo atingido cerca de $26 \mu \mathrm{mol} \mathrm{m}^{-2} \mathrm{~s}^{-1}$ de $\mathrm{CO}_{2}$. Em pastagens de Dactylis glomerata L., Peri et al. (2003) observaram que a fotossíntese foliar líquida diminuiu durante a rebrotação, de modo que no $60^{\circ}$ dia após o pastejo foi constatado queda de $42 \%$ relativo ao máximo observado no início da rebrotação.

Embora não seja possível dissociar o efeito dos dias de rebrotação e seus desdobramentos na idade das plantas e concentração de $\mathrm{N}$ do efeito da IL pelo dossel, verifica-se que, durante as estações do ano, a fotossíntese foliar líquida atingiu valores máximos entre o $11^{\circ}$ e $22^{\circ}$ dia (Tabela 3 ), em que a interceptação de luz média situou-se entre 90 e $96 \%$. Peri et al. (2003) observaram que, a partir do $25^{\circ}$ dia de rebrotação, quando a IL alcançou cerca de $90 \%$, a fotossíntese foliar líquida de $D$. glomerata reduziuse, e a partir do $35^{\circ}$ dia, quando a IL alcançou $95 \%$, a queda se tornou ainda mais pronunciada. Estudos com plantas forrageiras tropicais têm demonstrado que o manejo em lotação intermitente deve obedecer a critérios objetivos e um deles é a altura de entrada e saída dos animais do piquete (Marcelino et al., 2006; Barbosa et al., 2007). Essas alturas devem assegurar a manutenção de crescimento vigoroso da forrageira e, ao mesmo tempo, elevado consumo voluntário individual dos animais, sobretudo de folhas. Nesse sentido, a redução nos valores de fotossíntese foliar em dosséis com interceptação luminosa próxima de $100 \%$ é consequência da baixa eficiência fotossintética, e reflete

Tabela 3. Fotossíntese foliar líquida $\left(\mu \mathrm{mol} \mathrm{m} \mathrm{m}^{-2} \mathrm{~s}^{-1}\right.$ de $\left.\mathrm{CO}_{2}\right)$ em pastagens de capim-tanzânia ao longo de quatro épocas (verão, outono, inverno e primavera) e sob efeito do período de rebrotação (1, 11, 22 e 33). Os polinômios ortogonais (linear, quadrático e cúbico) são indicados para o efeito do período de rebrotação.

\begin{tabular}{ccccc}
\hline Dia de rebrotação & \multicolumn{4}{c}{ Época do ano } \\
\cline { 2 - 5 } & Verão & Outono & Inverno & Primavera \\
\hline 1 & 33,5 & 15,9 & 14,6 & 8,8 \\
11 & 38,6 & 26,0 & 16,6 & 20,0 \\
22 & 32,4 & 20,8 & 27,6 & 22,5 \\
33 & 29,0 & 20,6 & 21,0 & 23,0 \\
\hline Erro-padrão da média & 0,81 & 0,67 & 0,93 & 0,85 \\
\hline Polinômio ortogonal & \multicolumn{4}{c}{ p (probabilidade) } \\
Linear & 0,0015 & 0,1656 & $<0,0001$ & $<0,0001$ \\
Quadrático & 0,0020 & 0,0002 & 0,0042 & 0,0016 \\
Cúbico & 0,0197 & 0,0010 & 0,0001 & 0,3446 \\
\hline
\end{tabular}

a queda na taxa instantânea de acúmulo de forragem e, no caso de gramíneas tropicais, o aumento da taxa de crescimento de colmos. Também o decréscimo da fotossíntese foliar líquida ao final da rebrotação pode estar relacionado à expansão da bainha foliar nos perfilhos, em decorrência do aumento da distância percorrida pelas folhas em formação dentro da bainha. Isso torna as folhas recém-expandidas em folhas mais velhas do que aquelas cuja bainha é reduzida, o que diminui sua capacidade fotossintética (Peri et al., 2003).

Diferenças na estrutura do dossel entre espécies de clima temperado e espécies de clima tropical podem explicar diferentes padrões de respostas fotossintéticas. Em plantas de clima temperado, as folhas crescem mais próximo ao solo, onde o autossombreamento é maior com o aumento do IAF. Em gramíneas tropicais, especialmente as eretas e de hábito cespitoso, o crescimento de novas folhas ocorre em alturas mais elevadas do dossel, e isto minimiza o efeito da baixa quantidade de luz disponível às folhas em formação, decorrente do aumento do IAF. Apesar disso a resposta da fotossíntese durante a rebrotação foi similar àquela registrada para gramíneas temperadas (Woledge 1973; Grant \& King, 1984), em que a fotossíntese das folhas remanescentes ao pastejo é mais baixa. Dias-Filho (2002) concluiu que a fotossíntese do capim-marandu [Brachiaria brizantha (Hochst. ex A. Rich.) Stapf] e da B. humidicola (Rendle) Schweick foi reduzida com o sombreamento.

Entre os fatores que afetam a capacidade fotossintética de folhas individuais está a condição do dossel, que altera o ambiente luminoso no qual as folhas mais novas se desenvolvem (Allard et al., 1991). Le Roux \& Mordelet (1995) concluíram que a redução na capacidade fotossintética de gramíneas que apresentam rota metabólica $\mathrm{C}_{4}$, em savanas africanas, foi consequência não somente da diminuição da concentração de $\mathrm{N}$, mas também do aumento do autossombreamento no dossel. Neste trabalho, a relação entre fotossíntese foliar líquida e altura do dossel não foi significativa (Figura 1), pois nos primeiros dias da rebrotação ocorreu concomitante aumento de fotossíntese e aumento da altura do dossel, relação que não se verificou no fim da rebrotação. Como a folha completamente expandida, na qual foi realizada a leitura de fotossíntese, teve seu desenvolvimento durante período de tempo imediatamente anterior ao 
da avaliação, é provável que a condição do dossel nesse período também influencie a capacidade fotossintética das folhas em desenvolvimento. Desse modo, quando a mesma relação entre fotossíntese foliar líquida e altura do dossel foi modificada - de modo que fosse estabelecida uma relação entre a altura no $1^{\circ}$ dia com a fotossíntese foliar líquida no $11^{\circ}$ dia, e assim sucessivamente até que a altura no $33^{\circ}$ dia fosse relacionada à fotossíntese no $1^{\circ}$ dia do ciclo de pastejo seguinte -, o ajuste da regressão polinomial entre as duas variáveis foi significativo (Figura 1). Esse segundo ajuste demonstrou com maior clareza que o aumento da altura do dossel esteve associado a um decréscimo na fotossíntese foliar líquida, observado com atraso de pelo menos 11 dias no caso específico do período de rebrotação, já que o efeito do autossombreamento do dossel se apresenta desde a formação da folha contida dentro da bainha foliar precedente, quando ainda é dependente de fotoassimilados das folhas mais velhas (Prioul et al., 1980b).

Apesar do controle da massa de matéria seca remanescente no pós-pastejo, a altura pós-pastejo do dossel aumentou, ao longo do experimento, de 20 a $30 \mathrm{~cm}$ no tratamento de menor massa remanescente; de 30 a $50 \mathrm{~cm}$ no tratamento de massa intermediária; e de $45 \mathrm{a} 65 \mathrm{~cm}$ no tratamento de maior massa remanescente.

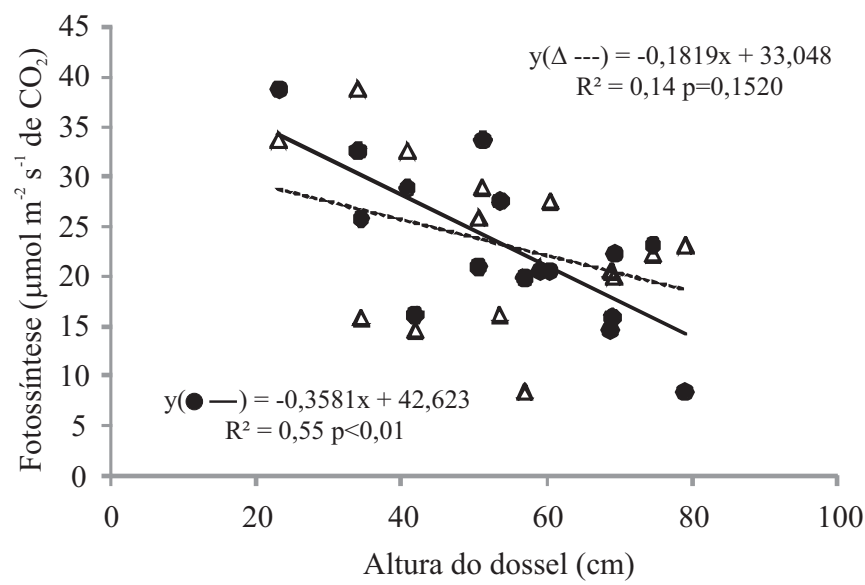

Figura 1. Resposta da fotossíntese foliar líquida ao aumento da altura do dossel, em pastagens de capimtanzânia; $(\Delta)$ relação direta entre altura do dossel e fotossíntese foliar; $(\bullet)$ relação entre altura do dossel e fotossíntese foliar: altura do $1^{\text {o }}$ dia com fotossíntese do $11^{\circ}$ dia e assim sucessivamente até que a altura do $33^{\circ}$ dia foi associada à fotossíntese do $1^{\mathrm{o}}$ dia do ciclo de pastejo posterior. Cada ponto representa a média de três intensidades de pastejo e quatro blocos experimentais.
Estudos com tratamentos de altura pós-pastejo em pastagens de capim-tanzânia recomendam a retirada dos animais do piquete quando a altura do dossel estiver entre 30 e $50 \mathrm{~cm}$ (Hodgson \& Da Silva, 2002).

Não houve efeito de tratamentos sobre a TAF, provavelmente em razão da utilização de períodos de descanso fixos, embora a planta sob elevada intensidade de pastejo também tenha capacidade de mobilização de reservas orgânicas e de alteração na arquitetura foliar, que compensam a perda de grande parte do aparato fotossintético durante o pastejo, ao menos no curto e médio prazos (Matches, 1992). Apesar de a fotossíntese foliar líquida não ter sido diferente entre os tratamentos, a capacidade fotossintética de todo o dossel, devido às diferenças em sua estrutura, pode ter sido influenciada pela presença de material morto e colmos de baixa capacidade fotossintética, que elevam as perdas respiratórias, reduzem a assimilação líquida do $\mathrm{CO}_{2}$ atmosférico e, consequentemente, reduzem a produção primária e o acúmulo de forragem. De modo geral, a variação da MF em razão do IAF foi relativamente bem explicada por uma equação linear de $\mathrm{R}^{2}=0,61$ (Figura $2 \mathrm{~A}$ ). Entretanto, quando o mesmo conjunto de dados foi discriminado entre tratamentos de intensidade de pastejo, observouse nítida distinção entre eles quanto à quantidade de MF associada ao IAF (Figura 2 B). Quanto maior a intensidade de pastejo, menor a MF para determinado IAF. Isso implica um gasto respiratório mais baixo, e como as taxas de acúmulo foram semelhantes entre tratamentos, conclui-se que a taxa assimilatória líquida nesses dosséis foi mais elevada, a fim de compensar o IAF mais baixo. Leriche et al. (2001) destacaram que, entre os principais benefícios do aumento da intensidade de pastejo no desempenho produtivo das plantas, estão a maior disponibilidade de luz no dossel e o aumento nas taxas fotossintéticas, em razão da remoção de tecido não fotossinteticamente ativo, efeito que, neste trabalho, em razão da utilização de períodos de descanso fixos, pode ter sido minimizado.

A influência da condição do dossel sobre a capacidade fotossintética individual das folhas é um aspecto adicional a ser considerado na elaboração de estratégias de manejo do pasto que tenham como meta a obtenção de forragem de alto valor nutritivo e, ao mesmo tempo, elevada produção de forragem, especialmente de folhas. Além disso, a utilização de parâmetros de fotossíntese foliar líquida em modelos de fotossíntese de dossel e assimilação de carbono deve 

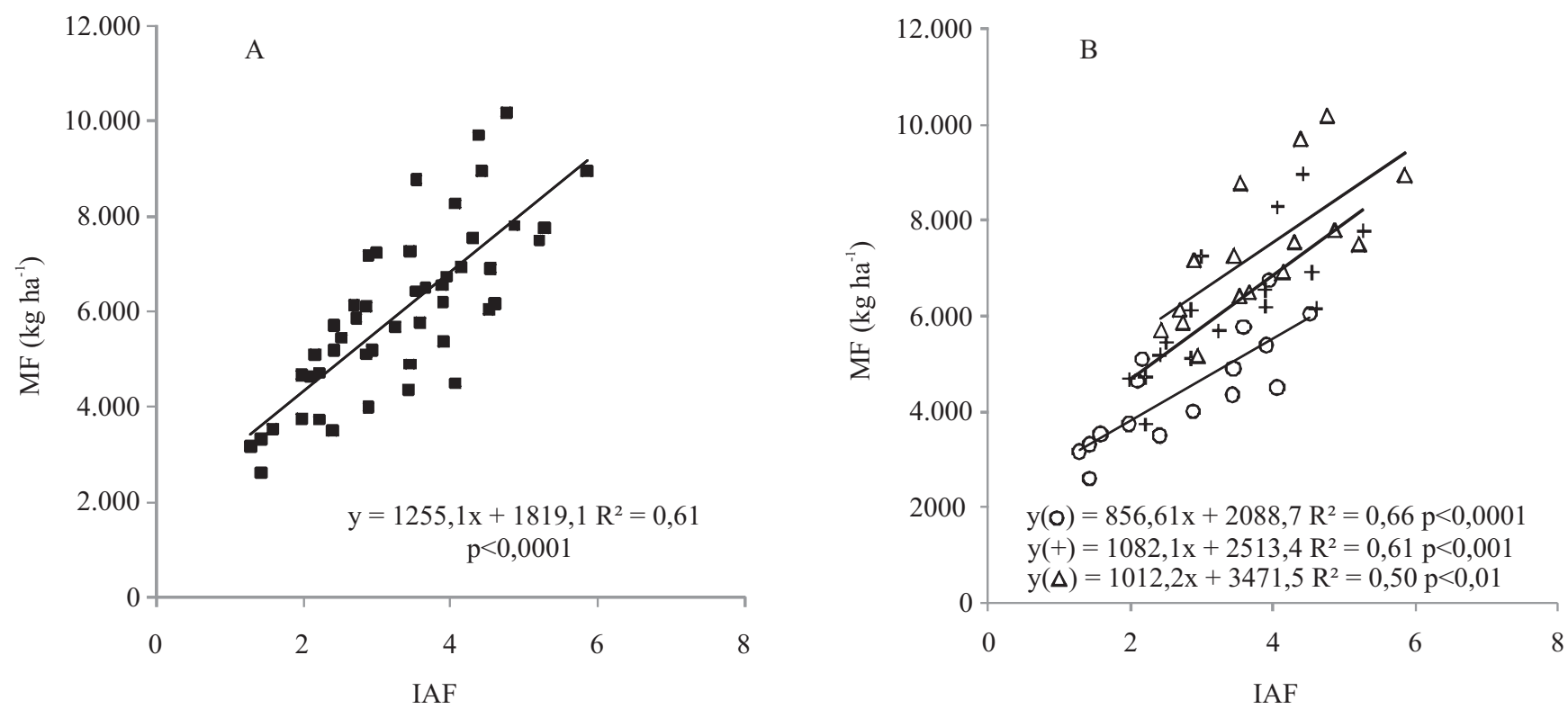

Figura 2. Relação entre a variação do índice de área foliar (IAF) e da massa de forragem (MF), em pastagens de capimtanzânia: A, valores sem distinção entre tratamentos; $\mathrm{B}$, tratamentos experimentais: $\mathrm{T}_{1}(\mathrm{O}), 1.000 \mathrm{~kg}^{-1}$ de matéria verde remanescente; $\mathrm{T}_{2}(+), 2.500 \mathrm{~kg} \mathrm{ha}^{-1}$ de matéria verde remanescente e $\mathrm{T}_{3}(\Delta), 4.000 \mathrm{~kg}^{-1}$ de matéria verde remanescente. Cada ponto representa a média de quatro blocos experimentais.

considerar, entre outros fatores, as alterações no dossel que, no caso da lotação intermitente, são marcantes. As alterações na estrutura do dossel têm reflexo no potencial assimilatório das folhas em desenvolvimento, o que repercute na capacidade fotossintética das folhas quando expandidas.

\section{Conclusões}

1. A variação na intensidade de pastejo, associada a períodos de descanso fixos, não é capaz de favorecer o aumento das taxas diárias de acúmulo de forragem.

2. A altura do dossel tem influência na capacidade fotossintética da folha durante sua formação, com reflexos posteriores, mesmo depois de sua completa expansão.

\section{Referências}

ALEXANDRINO, E.; GOMIDE, C.A.M.; CÂNDIDO, M.J.D.; GOMIDE, J.A. Período de descanso, características estruturais do dossel e ganho de peso vivo de novilhos em pastagem de capim-mombaça sob lotação intermitente. Revista Brasileira de Zootecnia, v.34, p.2174-2184, 2005.

ALLARD, G.; NELSON, C.J.; PALLARDY, S.G. Shade effects on growth of tall fescue. II. Leaf gas exchange characteristics. Crop Science, v.31, p.167-172, 1991.
BARBOSA, M.A.A. de F.; NASCIMENTO JÚNIOR, DOMICIO do; CECATO, U. Dinâmica da pastagem e desempenho de novilhos em pastagem de capim-tanzânia sob diferentes ofertas de forragem. Revista Brasileira de Zootecnia, v.35, p.1594-1600, 2006.

BARBOSA, R.A.; NASCIMENTO JÚNIOR, D. do; EUCLIDES, V.P.B.; SILVA, S.C. da; ZIMMER, A.H.; TORRES JÚNIOR, R.A. de A. Capim-tanzânia submetido a combinações entre intensidade e freqüência de pastejo. Pesquisa Agropecuária Brasileira, v.42, p.329-340, 2007.

BRAGA, G.J.; PEDREIRA, C.G.S.; HERLING, V.R.; LUZ, P.H.C.; LIMA, C.G. Sward structure and herbage yield of rotationally stocked pastures of 'Marandu' Palisadegrass [Brachiaria brizantha (A. Rich.) Stapf] as affected by herbage allowance. Scientia Agricola, v.63, p.121-129, 2006.

BROUGHAM, R.W. Interception of light by the foliage of pure and mixed stands of pasture plants. Australian Journal of Agricultural Research, v.9, p.39-52, 1958.

DIAS-FILHO, M.B. Photosynthetic light response of the $\mathrm{C}_{4}$ grasses Brachiaria brizantha and $B$. humidicola under shade. Scientia Agricola, v.59, p.65-68, 2002.

EMBRAPA. Centro Nacional de Pesquisa de Solos (Rio de Janeiro, RJ). Sistema Brasileiro de Classificação de Solos. Brasília: Embrapa-SPI, 1999. 412p.

GERDES, L.; WERNER, J.C.; COLOZZA, M.T.; CARVALHO, D.D. de; SCHAMMASS, E.A. Avaliação de características agronômicas e morfológicas das gramíneas forrageiras Marandu, Setária e Tanzânia aos 35 dias de crescimento nas estações do ano. Revista Brasileira de Zootecnia, v.29, p.947-954, 2000.

GRANT, S.A.; KING, J. Grazing management and pasture production: the importance of sward morphological adaptations 
and morphological photosynthesis. In: THE HILL FARMING RESEARCH ORGANIZATION. Biannual report: 1982-1983. London: British Grassland Society, 1984. p.119-129.

HODGSON, J.; DA SILVA, S.C. Options in tropical pasture management. In: REUNIÃO ANUAL DA SOCIEDADE BRASILEIRA DE ZOOTECNIA, 39., 2002, Recife. Anais. Recife: Sociedade Brasileira de Zootecnia, 2002. p.180-204.

LE ROUX, X.; MORDELET, P. Leaf and canopy $\mathrm{CO}_{2}$ assimilation in a West African humid savanna during the early growing season. Journal of Tropical Ecology, v.11, p.529-545, 1995.

LERICHE, H.; LE ROUX, X.; GIGNOUX, J.; TUZET, A.; FRITZ, H.; ABBADIE, L.; LOREAU, M. Which functional process control the short-term effect of grazing on net primary production on grasslands. Oecologia, v.129, p.114-124, 2001.

MACEDO, M.C.M. Análise comparativa de recomendações de adubação em pastagens. In: SIMPÓSIO SOBRE MANEJO DA PASTAGEM, 20., 2004, Piracicaba. Anais. Piracicaba: Fealq, 2004. p.317-356.

MARCELINO, K.R.A.; NASCIMENTO JÚNIOR, D. do; SILVA, S.C. da; EUCLIDES, V.P.B.; FONSECA, D.M. da. Características morfogênicas e estruturais e produção de forragem do capim-marandu submetido a intensidades $\mathrm{e}$ freqüências de desfolhação. Revista Brasileira de Zootecnia, v.35, p.2243-2252, 2006.

MATCHES, A.G. Plant response to grazing: a review. Journal of Production Agriculture, v.5, p.1-7, 1992.

PARSONS, A.J.; JOHNSON, I.R.; HARVEY, A. Use of a model to optimize the interactions between frequency and severity of intermittent defoliation and to provide a fundamental comparison of the continuous and intermittent defoliation of grass. Grass and Forage Science, v.43, p.49-59, 1988a.

PARSONS, A.J.; JOHNSON, I.R.; WILLIAMS, J.H.H. Leaf age structure and canopy photosynthesis in rotationally and continuously grazed swards. Grass and Forage Science, v.43, p.1-14, 1988b.

PEDREIRA, C.G.S.; ROSSETO, F.A.A.; SILVA, S.C.; NUSSIO, L.G.; MORENO, L.S.B.; LIMA, M.L.P.; LEME, P.R. Forage yield and grazing efficiency on rotationally stocke pastures of 'Tanzania-1' guineagrass and 'Guaçu' elephantgrass. Scientia Agricola, v.62, p.433-439, 2005.

PEDREIRA, B.C. e; PEDREIRA, C.G.S. Fotossíntese foliar do capim-xaraés [Brachiaria brizantha (A. Rich.) Stapf. cv. Xaraés] e modelagem da assimilação potencial de dosséis sob estratégias de pastejo rotativo. Revista Brasileira de Zootecnia, v.36, p.773-779, 2007.

PENATI, M.A. Estudo do desempenho animal e produção do capim-tanzânia (Panicum maximum Jacq.) em um sistema rotativo de pastejo sob irrigação em três níveis de resíduo pós-pastejo. 2002. 117p. Tese (Doutorado) - Escola Superior de Agricultura Luiz de Queiroz, Piracicaba.

PERI, P.L.; MOOT, D.J.; McNEIL, D.L.; LUCAS, R.J. Modelling net photosynthetic rate of field-grown cocksfoot leaves to account for regrowth duration. New Zealand Journal of Agricultural Research, v.46, p.105-115, 2003.

PRIOUL, J.L.; BRANGEON, J.; REYSS, A. Interaction between external and internal conditions in the development of photosynthetic features in a grass leaf. I. Regional responses along a leaf during and after low-light or high-light acclimation. Plant Physiology, v.66, p.762-769, 1980a.

PRIOUL, J.L.; BRANGEON, J.; REYSS, A. Interaction between external and internal conditions in the development of photosynthetic features in a grass leaf. II. Reversibility of lightinduced responses as a function of developmental stages. Plant Physiology, v.66, p.770-774, 1980b.

SANTOS, M.V.F.; DUBEUX JÚNIOR, J.C.B.; SILVA, M.C.; SANTOS, S.F.; FERREIRA, L.C.; MELLO, A.C.L.; FARIAS, I.; FREITAS, E.V. Produtividade e composição química de gramíneas tropicais na Zona da Mata de Pernambuco. Revista Brasileira de Zootecnia, v.32, p.821-827, 2003a.

SANTOS, P.M.; BALSALOBRE, M.A.A.; CORSI, M. Morphogenetic characteristics and management of Tanzania grass. Pesquisa Agropecuária Brasileira, v.38, p.991-997, 2003b.

SANTOS, P.M.; CORSI, M.; BALSALOBRE, M.A.A. Efeito da freqüência de pastejo e da época do ano sobre a produção e a qualidade em Panicum maximum cvs. Tanzânia e Mombaça. Revista Brasileira de Zootecnia, v.28, p.244-249, 1999.

SAS INSTITUTE. SAS/STAT user's guide. Version 7.1. Cary, NC, 1999.

WELLES, J.M.; NORMAN, J.M. Instrument for indirect measurement of canopy architecture. Agronomy Journal, v.83, p.818-825, 1991.

WOLEDGE, J. The photosynthesis of ryegrass leaves growth in a simulated sward. Annals of Applied Biology, v.73, p.229-237, 1973. 